Kalb, Christiane Heloisa; Flores, Maria Bernardete Ramos. Em busca da originalidade do patrimônio cultural na cidade-espetáculo: o caso da casa Boehm em Joinville/SC. GeoGraphos. [En línea]. Alicante: Grupo Interdisciplinario de Estudios Críticos y de América Latina (GIECRYAL) de la Universidad de Alicante, 2 de junio de 2016, vol. 7, no 87 (12), 17 p. [ISSN: 2173-1276] [DL: A 371-2013] [DOI: 10.14198/GEOGRA2016.7.87(12)].

\title{
Ge Graphos
}

\section{EM BUSCA DA ORIGINALIDADE DO PATRIMÔNIO CULTURAL NA CIDADE-ESPETÁCULO: O CASO DA CASA BOEHM EM JOINVILLE/SC}

\author{
Christiane Heloisa Kalb \\ Doutoranda do Programa de Doutorado Interdisciplinar em Ciências Humanas - PPGICH, \\ UFSC, Florianópolis, SC, Brasil \\ Mestre em Patrimônio Cultural e Sociedade, Univille; \\ Advogada atuante em Santa Catarina. \\ Christianekalb@hotmail.com \\ Maria Bernardete Ramos Flores \\ Professora Titular do Departamento de História da UFSC e Professora Colaboradora do \\ Programa Interdisciplinar em Ciências Humanas, UFSC, Florianópolis, SC, Brasil. \\ Graduada em História pela Universidade do Vale do Itajaí (1973), Mestre em História - UFSC \\ (1979), Doutora em História - PUC/SP (1991), Pós-Doutorado - Universidade Nova de \\ Lisboa/University of Maryland (1999-2000), Pós-Doutorado - IDAES - Universidad de San \\ Martín (2009-2010). \\ mbernaramos@gmail.com
}




\section{RESUMO}

Este trabalho tem o intuito de discutir como um imóvel tombado na cidade de Joinville/SC vem respondendo ao mundo das influências contemporâneas da espetacularização. A Casa Boehm, hoje uma loja de calçados no comércio, foi construída em 1927 e tombada em 2001, por meio do Processo de Tombamento PFCC n. 627/003, de 10 de abril de 2000, homologado pelo Decreto n. 3.461/2001, do Governador do Estado, na época, Esperidião Amin. O imóvel vem sofrendo alterações físicas, que afetam princípios de unidade, volumetria, padrões de estilo arquitetônico, o que faz com surjam debates a respeito dos seus valores estéticos. A depender do gosto dos locatários, especialmente no que se referee às cores externas, sem autorização, vislumbra-se a partir da opinião dos participantes do Conselho de Patrimônio da cidade - COMPHAAN, a espetacularização que este bem vem suportando em nome de uma sociedade de consumo, que apenas visa o lucro, apesar de inúmeros debates teóricos acerca da preservação. Desta forma, quando se pensa em restauração de um patrimônio cultural edificado, a preocupação imanente é com a sua imagem subjetiva/simbólica, e ainda, não menos importante, no que se refere às cores utilizadas nas pinturas das edificações. A metodologia utilizada é qualitativa, por meio de pesquisa bibliográfica, documentais no Arquivo Histórico de Joinville - AHJ e na Fundação Cultural de Joinville - FCJ e, etnográfica. A etnografia, com nuances interdisciplinares, foi realizada nestes mesmos Arquivos da cidade de Joinville, nos arredores do bem em questão e analisando algumas impressões obtidas nas reuniões do Conselho de Patrimônio da cidade - COMPHAAN. Este estudo é parte integrante da pesquisa para doutoramento em Ciências Humanas, na Universidade Federal de Santa Catarina - UFSC. Parte-se da hipótese inicial de que as discussões que envolvem as cores em bens tombados têm se relacionado com a autenticidade e a integridade dos conjuntos nos centros históricos. Porém, vai além, já que o espetáculo buscado pelos gestores públicos, com intento de valorizar suas cidades, acaba por homogeneizar esses territórios em torno de uma ideia de patrimônio que tem sido questionada por alguns teóricos.

Palavras-chave: Cidade-espetáculo, Patrimônio cultural, estética/cores, Joinville.

\section{EN BUSCA DEL PATRIMONIO CULTURAL DE ORIGINALIDAD EN LA CIUDAD- SHOW: EL CASO DE LA CASA BOEHM JOINVILLE / SC}

\section{RESUMEN}

Este trabajo tiene como objetivo analizar cómo una propiedad cayó en Joinville / SC ha respondido al mundo de influencias contemporáneas del espectáculo. La Casa Boehm, ahora una tienda de zapatos en el comercio, fue construido en 1927 y derrocado en 2001, a través del proceso de vuelco PFCC n. 627/003 de 10 de abril de 2000, aprobado por el Decreto n. 3461/2001, el Gobernador del Estado en el momento Esperidião Amin. La propiedad ha sufrido cambios físicos que afectan a los principios de unidad, los volúmenes, los patrones de estilo de arquitectura, lo que hace debates surgen acerca de sus valores estéticos. Dependiendo del gusto de los inquilinos, especialmente como árbitro para los colores exteriores, sin autorización, se vislumbra a partir de la opinión de los participantes en el Consejo del patrimonio de la Ciudad - COMPHAAN, el espectáculo que este bien se apoya en nombre de 
una empresa el consumo, que se refiere únicamente a los beneficios a pesar de numerosos debates teóricos sobre la conservación. Por lo tanto, cuando se piensa en la restauración de un conjunto de edificios del patrimonio cultural, la preocupación es inmanente con su imagen subjetiva / simbólico, y, no menos importante, en cuanto a los colores utilizados en las pinturas de los edificios. La metodología utilizada es cualitativa, por medio de la literatura, el documental en Joinville Historia Archivo - AHJ y la Fundación Cultural de Joinville - FCJ y etnográfico. Etnografía, con matices interdisciplinarios, se llevó a cabo en estos mismos archivos desde la ciudad de Joinville, en las inmediaciones de la propiedad en cuestión y analizar algunas impresiones obtenidas en las reuniones del Consejo de la Ciudad del patrimonio - COMPHAAN. Este estudio forma parte de una investigación para un doctorado en Ciencias Humanas, Universidad Federal de Santa Catarina - UFSC. Se inicia con la hipótesis inicial de que los debates que afectan a los colores que figuran edificios se han relacionado con la autenticidad y la integridad de los sistemas en los centros históricos. Sin embargo, va más allá, ya que el espectáculo buscado por los administradores públicos, con la intención de mejorar sus ciudades, en última instancia, homogeneizar estos territorios alrededor de un activo que la idea ha sido cuestionada por algunos teóricos.

Palabras clave: Ciudad - show, el patrimonio cultural, estética / de color, Joinville.

\section{IN SEARCH OF ORIGINALITY OF CULTURAL HERITAGE IN THE CITY - SPECTACLE: THE CASE OF BOEHM'S HOUSE IN JOINVILLE / SC}

\section{ABSTRACT}

This paper aims to discuss how a property tumbled in Joinville / SC has responded to the world of contemporary influences the spectacle. The Boehm'S House, now a shoe store in trade, was built in 1927 and overthrown in 2001, through the process Tipping PFCC n. 627/003 of 10 April 2000, approved by Decree n. 3461/2001, the State Governor at the time Esperidião Amin. The property has undergone physical changes that affect the principles of unity, volumes, architectural style patterns, which makes debates arise about their aesthetic values. Depending on the taste of tenants, especially as referee for external colors, without authorization, one glimpses from the opinion of the participants of the Board of City Landmark - COMPHAAN, the spectacle that this good is supporting on behalf of a company consumption, referring only to profit despite numerous theoretical debates about the preservation. Thus, when thinking about restoring a cultural heritage buildings, the immanent concern is with its subjective / symbolic image, and, not least, as regards the colors used in the paintings of buildings. The methodology used is qualitative, by means of literature, documentary in Joinville History Archive - AHJ and Cultural Foundation of Joinville - FCJ and ethnographic. Ethnography, with interdisciplinary nuances, was carried out in these same files from the city of Joinville, in the vicinity of the property in question and analyzing some impressions obtained in the meetings of the Board of City Landmark - COMPHAAN. This study is part of research for a $\mathrm{PhD}$ in Human Sciences, in Federal University of Santa Catarina - UFSC. It starts with the initial hypothesis that discussions involving the colors 
listed buildings have been related to the authenticity and the integrity of the sets in the historic centers. However, goes beyond, since the show sought by public administrators, with intent to enhance their cities, ultimately homogenize these territories around an asset that idea has been questioned by some theorists.

Keywords: City - spectable, cultural heritage, aesthetics / color, Joinville.

\section{INTRODUÇÃO}

A Casa Boehm, construída em 1927, hoje é uma loja de calçados no comércio central da cidade de Joinville. Os proprietários iniciais desse bem são Carlos Frank Jr. e Bernardo Boehm, e ambos receberam as Notificações de n. 030/94 e 150/98 para fins de impugnar o tombamento municipal. Este imóvel foi tombado em 2001, por meio do Processo de Tombamento PFCC n. 627/003, de 10 de abril de 2000, homologado pelo Decreto n. 3.461/2001, do Governador do Estado, na época, Esperidião Amin.

O imóvel vem sofrendo alterações físicas, que afetam princípios de unidade, volumetria, padrões de estilo arquitetônico, o que faz com que surjam debates, dentro da Comissão de Patrimônio Cultural da cidade - COMPHAAN, a respeito dos seus valores estéticos. Afinal, a depender do gosto dos locatários ou proprietários, especialmente no que se refere às cores externas, há alterações no imóvel sem autorização do órgão fiscalizador, vislumbrando-se a partir da opinião dos participantes da COMPHAAN a espetacularização que este bem vem suportando apenas visando o lucro, apesar de inúmeros debates teóricos acerca da preservação.

Desta forma, quando se pensa em restauração ou manutenção de um bem patrimonializado, a preocupação imanente é com a sua imagem subjetiva e simbólica, e ainda, não menos importante, o que se refere às cores utilizadas nas fachadas dessas edificações, a comunicação visual e o entorno desses bens.

Este estudo é parte integrante da pesquisa para doutoramento em Ciências Humanas, na Universidade Federal de Santa Catarina - UFSC. Parte-se da hipótese inicial de que as discussões que envolvem a estética em bens tombados têm se relacionado com a autenticidade e a integridade dos conjuntos nos centros históricos. Porém, vai além, já que o espetáculo buscado pelos gestores públicos, com intento de valorizar suas cidades, acaba por homogeneizar esses territórios em torno de uma ideia de patrimônio que tem sido questionada contemporaneamente.

\section{DIREITO OU DEVER DE ESCOLHA - IDENTIDADE GERMÂNICA RECRIADA}

A Casa Boehm participa da recriação simbólica das identidades dos habitantes da cidade de Joinville, uma identidade ainda fixada de germanidade. Ressalta-se a ideia de uma Joinville não isolada do mundo, mas ligada eternamente à Antiga Alemanha, dos tempos de seus colonizadores, já que em meados do século XIX foi fundada por imigrantes germânicos. 
Porém, já desde a década de 1960, Joinville se tornou uma cidade cosmopolita, palco de disputas simbólicas por vários grupos sociais, não só afixados pela tradição germânica. No entanto, mesmo após essa transformação urbana significativa, as mídias, os órgãos públicos e privados do turismo todos aliados à Comissão de Patrimônio da cidade mantém um ideal passadista e preservacionista em prol da identidade germânica.

Silveira e Bezerra (2007, p. 92), nesse sentido, afirmam que o poder de arbitrar sobre o patrimônio do Outro, no nosso caso, da população joinvillense, como um bem estadual (museificando, decretando sítios e parques) desloca a noção de hereditariedade do local para o geral, revelando que a autenticidade e o valor do bem - seja ele histórico, artístico, arquitetônico, arqueológico, entre outros - são regidos pela apreciação e pelo gosto de determinados experts $^{l}$ sobre o assunto. Esses experts podem ser considerados os integrantes da COMPHAAN, bem como, da Fundação Cultural de Joinville, que nem sempre consideram o olhar daquele que opera (no sentido cognitivo e prático) com o bem no seu cotidiano.

Ou seja, o próprio ato de lidar com o patrimônio material pelos grupos humanos nos quais eles emergem como elementos do vivido coloca o fato da imaterialidade como uma questão central: antes de os "usos culturais da cultura" (MENESES, 1999) surgirem como um fato da política estatal de patrimonializar, os significados desses bens são fatos de cultura, e, ao descontextualizarmos tais fatos, ferimos a própria noção de patrimônio imaterial (SILVEIRA; BEZERRA, 2007). É necessário um constante exercício de desconstrução desta lógica patrimonial do Estado.

E é exatamente esse um dos intentos desse estudo, descontruir a lógica estatal, de políticas públicas em prol do patrimônio, em que pese, nem sempre se preocupar com os realmente interessados por seu patrimônio, a população do entorno, que usa e usufrui destes bens e mais, políticas que somente se preocupam em manter uma identidade homogeinizadora, no caso de Joinville, a identidade germânica.

Sobre o bem, propriamente dito, posso dizer, primeiramente, que a Casa Boehm como é conhecida entre os profissionais do patrimônio, ou "Apolo Calçados", para a população em geral joinvillense, é um caso diferenciado. A casa está em boa conservação estrutural, sendo utilizada pelo comércio de calçados, ou seja, não se desvirtuou de seu fim, já que inicialmente, quando construída em 1927, já era destinada ao uso comercial. Entretanto, atualmente, sua estética é motivo de piada na cidade. A casa está pintada com as cores roxo e branco (fig 1) destoando completamente do "original", uma pintura em tons pastéis, o que vem causando alvoroço entre os defensores do patrimônio.

\footnotetext{
${ }^{1}$ Giddens (1991) chama esses experts de "peritos", por serem especialistas em determinado assunto, a ponto de deter certo poder de decisão sobre tal aspecto. "Por sistemas peritos quero me referir a sistemas de excelência técnica ou competência profissional que organizam grandes áreas dos ambientes material e social em que vivemos hoje".
} 
Figura 1 - Casa Boehm, Apolo Calçados, 2013.

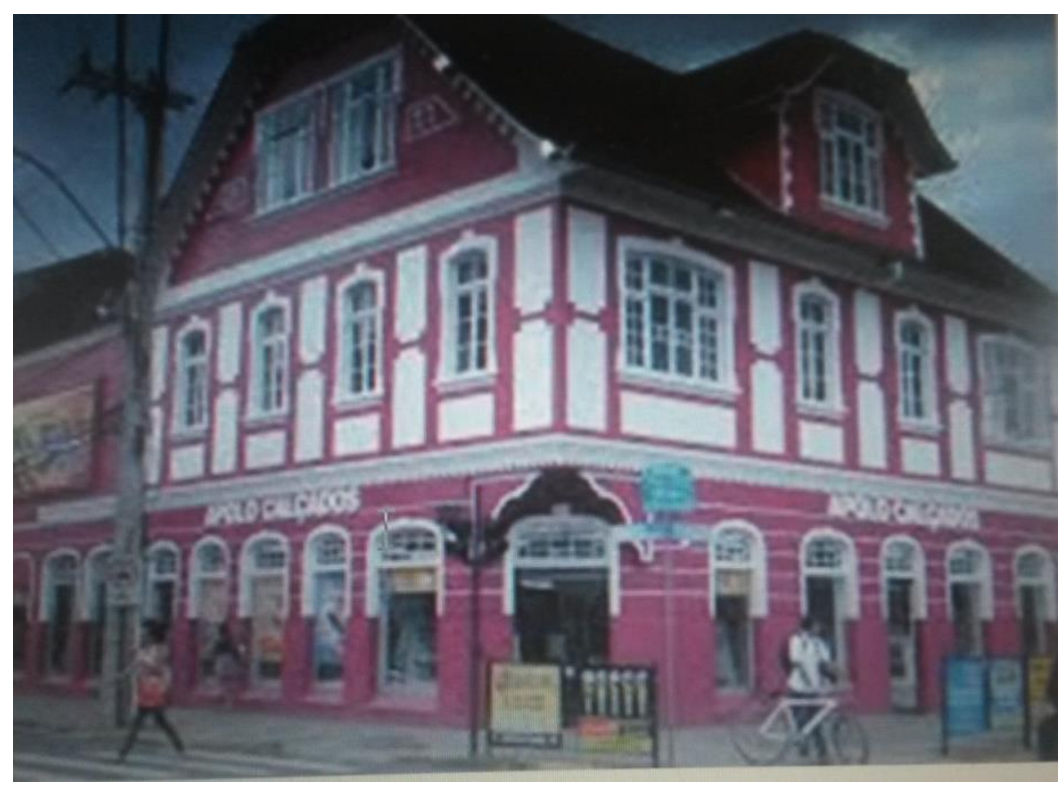

Fonte: <www.dascatarinas.com.br> Acesso: 29 maio 2015.

Alguns teóricos da contemporaneidade podem vir a responder algumas das questões que envolvem as transformações urbanas com o desenvolvimento da cidade como um todo. Além disso, a COMPHAAN também pode ter as respostas para boa parte desses questionamentos relacionados às novas discussões que surgem a partir da urbanização, o que veremos em seguida.

\section{A ESTÉTICA VISUAL VERSUS A DESCARACTERIZAÇÃO DA AUTENTICIDADE}

As alterações não autorizadas na pintura da Casa Boehm demonstram a falta de interesse dos locatários em preservar as condições estéticas "originais" desse bem. Apesar de haver discussões sobre a originalidade das cores da pintura externa de bens tombados, vislumbra-se claramente na opinião externada pelos participantes da COMPHAAN, a descaracterização que esse bem vem sofrendo em nome de uma sociedade, que apenas visa o lucro.

Sobre a pintura de bens tombados:

Durante a reunião foram apresentadas algumas questões que devem ser decididas pela Comissão. E no ínterim é levantada uma questão que me parece particularmente interessante. Qualquer modificação estritamente estética em bens tombados é avisada/comunicada à Comphaan? Alguns dizem que não, pois pintura é um ponto de modificação que não é requerida a sua autorização perante a Comphaan, nem ao Seinfra, diz a integrante que é representante do Seinfra. Na lei não diz nada sobre a pintura dos bens imóveis tombados, ela confirma. Para o Seinfra, todas as obras nesses bens precisariam ser aprovadas pela Comphaan e pelos Bombeiros [Diário de Campo 09/07/2014 $1^{\mathrm{a}}$ reunião]. 
Lembrando, como conceitua Yazigi (2006, p.70), o sentido etimológico de estético é a experiência da sensação pela potencialização da forma. Assim, os valores estéticos de um edifício, por exemplo, refletem em princípio de unidade, volumetria e outras ordenações, como padrões de estilo e gosto pessoal.

Castells e Nardi (2012, p. 260) expõem que a imagem urbana começa a evidenciar a incongruência que existe entre os atuais requerimentos de instalações e organização do espaço público/privado frente às limitadas alternativas que podem oferecer velhos casarões, como é o caso da Casa Boehm, dos anos 1920.

A consequência é que os proprietários/locatários começam a efetuar alterações na disposição interna das unidades, o que se traduz nas fachadas em mudanças muito significativas em termos de visibilidade oferecida, tal como troca no tipo e dimensões de esquadrias ou na cor e materiais usados no tratamento das superfícies frontais. Com essas "permissividades" (já que muitas obras são feitas de maneira quase clandestina sem sofrerem embargo por parte da Prefeitura Municipal ou no nosso caso, da Fundação Cultural de Joinville - FCJ).

A cidade vai aos poucos perdendo a imagem de "cidade antiga", de ser localidade escolhida como cenário icônico perpetuador da tradição germânica. Na tentativa de buscar corresponder a um imaginário idealizado e congelado no tempo, o paradoxal (ou a consequência) é que inegavelmente vai se deteriorando a imagem original da cidade, a qual tende a ir se convertendo cada vez mais em um mosaico de fragmentos sem um caráter definido.

Conforme descrição de Althoff (2008, p. 158), a edificação em questão é de grande porte, com dois pisos e meio, em linguagem teuto-brasileira expressa, principalmente pelo tipo de telhado com grande inclinação e aberturas do tipo mansarda. Como a grande maioria das unidades, conjuga uso comercial e residencial. Edificada em 1927, é o ponto focal da Rua Visconde de Taunay e da Av. Juscelino Kubistchek. O térreo é ocupado por uma tradicional loja de calçados, Apolo Calçados, cujo acesso principal se dá pela esquina e conta com o mesmo tipo de entrada encontrado na edificação que fica na Rua Dr. João Colin, n 349. A cor adotada para o térreo (fig. 1 acima) procura reforçar a referência do ponto comercial, em detrimento do equilíbrio visual e coerência histórica.

A descaracterização consonante à pintura/cores de um determinado bem protegido não é novidade junto aos autores que tratam dessa temática, aliada ao patrimônio histórico-cultural. Desde a Conferência de Veneza (1964) esse tema já vinha sendo discutido internacionalmente, tanto que seu artigo $6^{\circ}$ menciona que:

A conservação de um monumento implica a preservação de um esquema à sua escala. Quando o esquema tradicional subsiste, ele será conservado e toda construção nova, toda destruição ou todo ordenamento que poderia alterar as relações de volumes e de cores será proscrito.

O tema aliado à noção de monumento para fins de preservação de memória de certos edifícios fez com que a Carta de Veneza se preocupasse com a preservação de zonas de ambiência e não somente com o edifício em si (YAZIGI, 2006, p. 69).

Mais antigo que a Carta é o exemplo trazido por Choay (2011, p. 112). Segundo Choay, Victor Hugo, já em 1825, escreveu a “Guerra aos demolidores!”, artigo que envolve as áreas 
de Literatura e Filosofia, que fala sobre restaurações mal sucedidas em bens protegidos, especialmente no que se refere à pintura.

A catedral gótica de Autun sofreu o mesmo ultraje. Quando passamos em Lyon, em agosto de 1825, há dois meses, fazia-se desaparecer igualmente sob uma camada de têmpera rosa a bela cor que os séculos deram à catedral do primado dos Gauleses [...]. Quaisquer que sejam os direitos da propriedade, a destruição de um edifício histórico e monumental não deve ser permitida. Há duas coisas em um edifício: seu uso e sua beleza. Seu uso pertence ao proprietário, sua beleza a todo mundo, portanto é melhor suplantar seu direito que destruir o edifício.

Quando falamos em restauração de um patrimônio cultural edificado, a preocupação imanente é com a imagem desse bem, principalmente no que se refere às cores utilizadas nas pinturas das edificações. As discussões que envolvem as cores têm relação com a autenticidade e integridade dos conjuntos. Althoff $(2008$, p.48) complementa dizendo que a cidade é um espaço simbiótico, em razão do poder político em relação à sociedade civil, e um espaço simbólico, pois integra culturalmente, dá identidade coletiva a seus habitantes e tem um valor de marca de dinâmica com relação ao exterior.

Nesse sentido, exemplo interessante que vem ocorrendo desde os anos 2000 é a ação de recuperação urbana e restauro de bens tombados e centros históricos, do governo através do Programa Monumenta. De acordo com Althoff (2008, p. 58), este é um programa estratégico do Ministério da Cultura, financiado pelo Banco Interamericano de Desenvolvimento, e apoiado pela UNESCO, que tem por objetivo a recuperação sustentável do patrimônio, a conscientização da população residente nos centros históricos e o estímulo à utilização cultural, social e econômica das áreas selecionadas. Uma das cidades escolhidas para receber o programa Monumenta foi São Francisco do Sul - próximo a Joinville 60Km, tendo seu centro histórico tombado desde 1987.

Althoff $(2008$, p. 118) lembra que na gestão do prefeito de Joinville, Wittich Freitag, entre 1983-1988, foi realizado um projeto de revitalização urbana na cidade, o Projeto Caminhar no Centro. Esse projeto tinha a intenção de despoluir as fachadas, renovar os pavimentos dos passeios, utilizando petit-pave $\hat{e}^{2}$ e desenhos de bicicletas (fig.2), lembrando o transporte símbolo da cidade.

\footnotetext{
${ }^{2}$ Petit-pavê é um tipo de calçamento, normalmente feito em forma de mosaico, com pedras em formato irregular quadrado pretas e brancas. O modelo bem conhecido brasileiro é a calçada de Ipanema e Copacabana, no Rio de Janeiro.
} 
Figura 2 - Petit-pavê em Joinville, 2014.

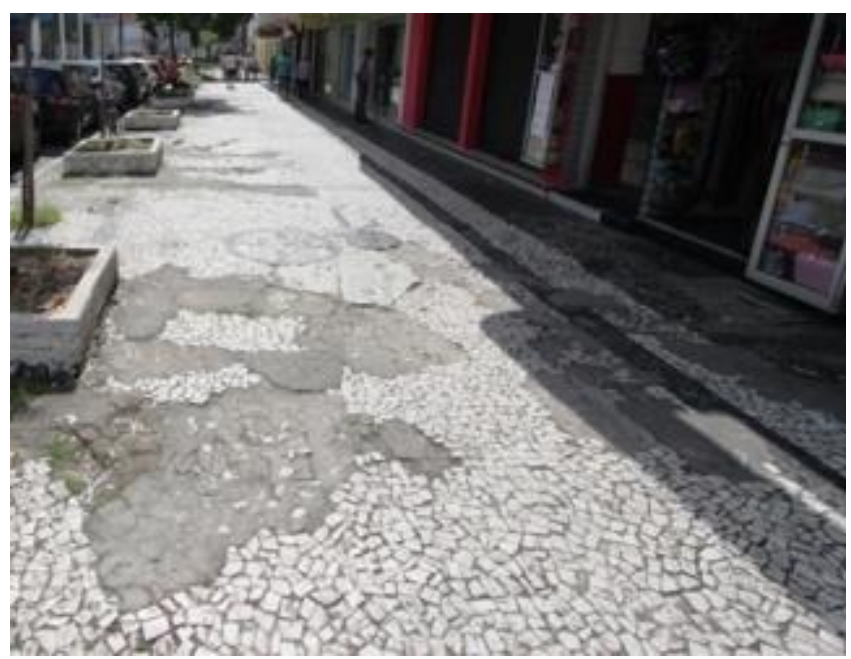

Fonte: <www.ndonline.com.br> Acesso: 29 maio 2015.

Na figura 2 se pode perceber, que apesar da reforma da década de 1980, o passeio já se encontra bastante deteriorado, e o problema maior é a dificuldade em encontrar profissionais habilitados para reconstituir os desenhos das bicicletas.

Em 1998, outro projeto de valorização urbana, coordenado pela FCJ em conjunto com a CONURB, foi feito para despoluir visualmente o centro da cidade. Esse projeto, de iniciativa privada, que envolveu a Fundação Roberto Marinho e fabricantes de tintas, foi chamado de Projeto Cores da Cidade - Joinville. As edificações que aderiram ao projeto foram Hotel Anthurium, Lar Abdon Batista, Sociedade Harmonia-Lyra, Fininvest, Ipreville, Farmácia Minâncora e Metalúrgica Wetzel. Em Joinville, esse projeto não surtiu o mesmo efeito que em outras cidades brasileiras, como Salvador, no Pelourinho, Vitória, Fortaleza, já que a pintura se restringiu a alguns bens tombados individualmente, não gerando uma renovação urbana no conjunto (ALTHOFF, 2008, p. 129).

Castells e Nardi (2012, p. 25) afirmam ainda que tal projeto, como tantos outros, foi palco de tensões entre seus participantes e órgãos de preservação, inclusive, fazendo parte de uma mesma instância governamental. Isso provoca o que consideram da maior gravidade: o que estaria em jogo seriam os critérios a se adotar em relação às atribuições de valor aos bens escolhidos; as formas de tratamento desses bens; o papel do poder público referente a essas práticas.

Percebe-se, por meio destes projetos e programa, que o poder público tem uma agenda voltada à esteticização das fachadas dos bens tombados e inventariados da cidade, porém nem sempre são efetivos em sua totalidade. Os interesses que se mostram ocultos nestes projetos acabam por prejudicam a manutenção destes bens, isolados ou em conjunto, colocando em risco atitudes que poderiam ser consideradas positivas se levadas a sério, inserindo espaços públicos e privados, antes esquecidos e abandonados, na reatividade da cidade. 


\section{A COMUNICAÇÃO VISUAL E O ENTORNO DE BENS TOMBADOS}

A lei complementar n. $175 / 2004$ prevê em seus artigos $4^{\circ}$ e $5^{\circ}$ a proibição de veiculação de comunicação visual que obstrua a visão do patrimônio ambiental urbano, o que inclui o patrimônio cultural joinvillense. Apesar de haver controle legal quanto à comunicação visual da cidade, principalmente na área urbana, vemos uma verdadeira confusão visual na área de proteção dos bens tombados. Há gigantescos letreiros, placas publicitárias que são os maiores responsáveis pela falta de clareza na paisagem urbana, além de outros inconvenientes necessários, como placas de ruas, de trânsito, postes de iluminação pública e ainda as redes de energia elétrica e de telecomunicações.

Lopes (2011, p. 43) discute essa questão, lembrando que o crescimento econômico e populacional das cidades frente a algumas ações necessárias para conter a expansão urbana tenta apaziguar os conflitos espaciais. Para tanto, o autor cita Benevolo (1991, p. 71) que esclarece que a convivência entre o centro histórico e a periferia não é fácil, pois os espaços livres da cidade antiga foram preenchidos pela modernidade, as ruas foram atingidas por um tráfego intenso de carros, motos e veículos grandes que é incompatível com a infraestrutura da cidade. Inicialmente construída para veículos pequenos e com pouco movimento/tráfego.

O que ocorre especialmente a rua lateral a Casa Boehm, por onde passa atualmente apenas uma via de veículos, diferente de quase 100 anos atrás (fig.3), quando a via era de estrada de chão e transitada tranquilamente dois veículos.

Figura 3 - Rua Dr. João Colin (antiga Nordstrasse - rua do Norte - e rua Cruzeiro), no trecho entre a 15 de Novembro e a Nove de Março.

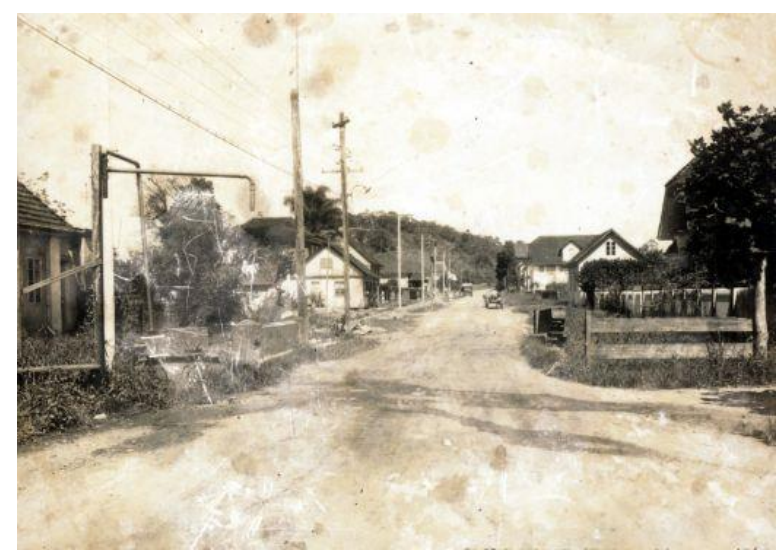

Fonte: <http://wp.clicrbs.com.br/anmemoria/2014/01/10/an-memoria-de-sexta-que-lugar-e-este48/?topo=84,2,18,,,77> Acesso: 29 maio 2015.

A figura acima é uma fotografia feita na década de 1920, onde à esquerda, aparece parte do prédio da família Boehm (hoje ocupado pela Calçados Apolo), que parecia estar ainda em construção. Adiante, também à esquerda, vê-se a chaminé das Indústrias Colin. A casa menor à direita pertenceu à família Grünsch. No mesmo lado, a casa seguinte era a residência e latoaria da família de Otto Pfuetzenreuter. As duas casas que aparecem ao fundo estão no início da rua Visconde de Taunay.

Portanto, com o passar das décadas e o consequente crescimento das cidades, o que deveria ser defendido pelos gestores públicos é o desvio de trânsito desses veículos grandes dos 
“centros históricos", mas não é o que ocorre. As margens externas dos centros históricos não se interligam com campo, ou seja, com a área rural, mas com as massas compactas dos bairros periféricos, ou seja, há um grande número de casas antigas que foram se transformando em escritórios e grandes lojas comerciais, mal-e-mal conservando a sua aparência exterior. Todas essas modificações comprimem e aviltam a coerência formal e funcional da cidade antiga e constituem as consequências da incompatibilidade estrutural entre os dois organismos, centro histórico e periferia. Entretanto, a surpreendente resistência do concatenado histórico e essas transformações demonstram que o mecanismo pós-liberal pode ser impugnado e suspenso.

Lopes (2011), neste sentido, lembra que a carta de Atenas, de outubro de 1931, já apresentava diretrizes referentes ao trato urbanístico do entorno das edificações de acordo com o trecho do item A, seção III:

recomenda-se, sobretudo, a supressão de toda a publicidade, de toda presença abusiva de postes e fios telegráficos, de toda indústria ruidosa, mesmo de altas chaminés, na vizinhança ou na proximidade dos monumentos, de arte ou de história.

Esta diretriz reflete uma preocupação, suscitada já há mais de 80 anos, referente à poluição visual, sonora e do ar nas regiões onde sem encontram os monumentos ou edificações consideradas patrimônio cultural, de forma a lhes causar danos, tanto físicos, como a deterioração direta de suas superfícies, quanto nas condições de uso e contemplação dos mesmos, e até mesmo do cenário onde se localizam.

O detalhe mais interessante a se destacar é que a demanda da rede atual de eletricidade é muito superior à da época do início das construções desses patrimônios. A poluição visual em Joinville ocorre da mesma forma acentuada, principalmente no bairro centro, onde as edificações alinhadas ao passeio se utilizam de grandes letreiros e outdoors para chamar a atenção dos transeuntes. E é uma situação que tende, automaticamente, a piorar, pois conforme as placas se tornam mais visíveis, os outros estabelecimentos aumentam também suas placas, utilizam faixas, efeitos sonoros e tudo o que for possível para atrair a atenção de possíveis consumidores (LOPES, 2011, p. 43).

Os elementos que conformam o patrimônio material variam ao longo do tempo em função de reações químicas, biológicas e mecânicas. As transformações são comumente referidas como "envelhecimento" e, não raras vezes, contribuem para dar um tom adicional aos elementos, a chamada "pátina" do tempo ou os "pequenos sinais de idade, que se acumulam nas superfícies dos objetos" (McCRACKEN, 2007, p. 32).

Esse processo pode ser acelerado ou retardado por medidas que favoreçam que um monumento, área, ou lugar perdure mais tempo ou desapareça mais rapidamente. Além disso, nem todos os fatores agressores têm a mesma implicação. Terremotos, erupções vulcânicas, inundações, deslizamentos de terra, furacões, tufões etc., são algumas das ameaças naturais que têm um efeito devastador e imediato sobre um bem. Outros têm ação gradual e cumulativa, com consequências visíveis apenas após certo período de tempo. Dentre esses, existem ações humanas negligentes, expressas na pressão urbana, na visitação turística incontrolada e na supremacia dos interesses econômicos. (IPHAN, 2004 apud ZANIRATO, 2008, p. 152). 
Atualmente, a Prefeitura de Joinville, através da CONURB, controla a comunicação visual nas edificações e é bem restritiva quando se trata de edificações históricas, visto que o projeto deve ser aprovado pela COMPHAAN. Todavia, esta ação isolada não resolve o problema como um todo, visto que todo o cenário urbano deve ser limpo deste tipo de poluição visual. $\mathrm{Na}$ verdade, as restrições às edificações antigas são importantes no sentido de não alterar suas características arquitetônicas, de não obstruir a visão ou aos seus detalhes construtivos e buscar o menor dano material possível para as edificações.

Além da poluição gerada pela comunicação visual, o bairro Centro da cidade de Joinville sofre com dois fatores interligados, a falta de arborização urbana nas ruas, que poderiam aliviar os impactos da poluição do ar e sonora, bem como refrescar e criar ambientes mais agradáveis, considerando o forte calor na cidade (LOPES, 2011, p. 136), e as constantes enchentes (fig.4), que afetam tanto os bens tombados, quanto aos não protegidos.

Figura 4 - Enchente na praça em frente à Casa Boehm, 2011.

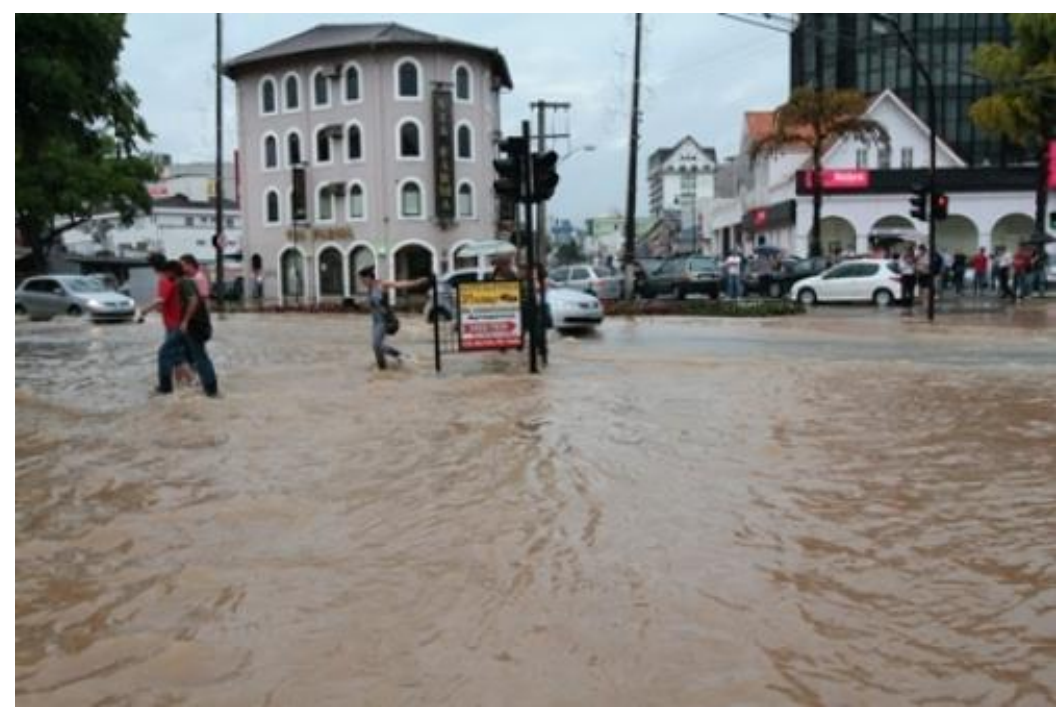

Fonte: <http://www.ndonline.com.br/joinville/noticias/21840-volta-a-alagar-em-oinville.html> Acesso: 29 maio 2015.

Assim, percebe-se que a cidade de Joinville, e especificamente, o bairro Centro são alvos fáceis da desvalorização estética por eventos climáticos e ações humanas.

\section{O PATRIMÔNIO COMO ESPETÁCULO DAS CIDADES}

Analisando o caso da Casa Boehm ao qual vem sofrendo com a descaracterização estética, em razão da pintura de sua fachada em cores marcantes, bem como, pelas recorrentes enchentes, se apreende a necessidade de discutir a cultura como mercadoria a ser comercializada. Nessa perspectiva, a cultura de determinada localidade é posta como uma cidade-vitrine, que pode ser vista, fotografada, vendida, compartilhada.

Michel Certeau (2013, p. 88 e p. 90), ao discutir a mercantilização da cultura, menciona que, na realidade, diante de uma produção racionalizada, expansionista, centralizada, espetacular e barulhenta, posta-se uma produção do tipo totalmente diverso, qualificada como "consumo" 
que tem como característica suas astúcias, seu esfarelamento em conformidade com as ocasiões, suas "piratarias", sua clandestinidade, seu murmúrio incansável, em suma, uma quase invisibilidade, pois ela quase não faz notar por produtos próprios (onde teria o seu lugar?), mas por uma arte de utilizar aqueles que lhe são impostos.

Assim, aquilo que se chama de "vulgarização" ou "degradação" de uma cultura seria então um aspecto, caricaturado e parcial, da revanche que as táticas utilizadoras tomam do poder dominador da produção. Seja como for, o consumidor não poderia ser identificado ou qualificado conforme os produtos jornalísticos ou comerciais que assimila: entre eles (que deles se serve) e esses produtos (indícios da "ordem" que lhe é imposta), existe o distanciamento, mais ou menos grande, do uso que faz deles. E ainda, seja como for, na escala da história contemporânea, parece também que a generalização e a expansão da racionalidade tecnocrática criaram, entre as malhas do sistema, um esfarelamento e um pulular dessas práticas antigamente reguladas por unidades locais estáveis. Cada vez mais as táticas vão saindo de órbita. Desancoradas das comunidades tradicionais que lhes circunscreviam o funcionamento, elas se põem a vagar por toda a parte num espaço que se homogeniza e amplia.

Os consumidores se tornam migrantes por meio do turismo e do consumo. O sistema onde circulam é demasiadamente amplo para fixá-los em alguma parte, mas demasiadamente regulamentado para que possam escapar dele e exilar-se alhures. A discussão de Certeau nos leva a pensar sobre como a cultura tem sido vista muito mais como algo a ser consumido e, portanto, experienciada para ser transformada, aliada ao turismo, ao invés de praticada para a continuidade de sua existência.

As cidades, por meio de seus órgãos gestores da cultura, normalmente interligados ao do turismo, fazem de tudo para que haja atividades suficientes para os turistas. Eles vêm às cidades, a visitam, sentem a fictícia experiência dos moradores locais e vão embora, com a impressão de ter cumprido o papel de consumidores de cultura e de terem preenchido a "lista" consumível destes locais. Dessa maneira, aliado ao pensamento de Certeau (2013), Castells e Nardi (2012, p.11) defende que a "questão da reabilitação dos centros urbanos, no contexto do fenômeno da globalização" pode ser vista "como um processo de homogeneização".

Certeau (2013, p. 255) finaliza sua ideia sobre a mercantilização da cultura dizendo que não deixam de se formar, com todo o tipo de "integristas", associações ideológicas e financeiras com o intuito de reparar essas náufragas da história e fazer das igrejas museus de crenças sem crentes, ali guardadas para serem exploradas pelo capitalismo liberal. Ou seja, deixar que as igrejas sejam consumidas pelos turistas.

Para Silveira e Bezerra (2007, pp. 90-91) neste sentido:

Há um complexo processo de socialização no corpo de uma sociedade que está apoiado num, não menos complexo, sistema de aprendizagens cotidianas, em que as interpretações e representações do mundo significam a partir do lugar em que são engendradas pelos agentes sociais. Um objeto qualquer, uma edificação antiga ou uma ruína tomada pela relva, por certo, jamais estão isentas de significação para o grupo que os vivencia cotidianamente. As coisas não estão fora do lugar. De fato, estes elementos materiais que se perpetuam na paisagem não são, em si, a memória, mas a sua fonte. São, portanto, a base material para a construção do imaginário histórico (JEUDY, 1990). Sendo assim, as paisagens patrimoniais seriam, 
antes de um bem de caráter nacional voltado para as experiências turísticas, aqueles "lugares praticados" (CERTEAU, 2004) nos quais as pessoas realizam as suas atividades cotidianas de forma a manterem viva uma determinada herança cultural. Este acervo comum não diz respeito apenas às coisas materiais, mas também a um conjunto de imagens e de ideias compartilhado que dinamiza o "espírito do lugar", ao mesmo tempo em que a elasticidade da memória coletiva (HALBWACHS, 1990) - a memória enquanto um espaço fantástico (ROCHA \& ECKERT, 2005) - revela o jogo sutil entre lembrança e esquecimento como algo relevante para as pessoas.

Nesse sentido, Acselrad (2009, pp. 181-182) alega que guardadas as diferenças e matizes entre os variados projetos, pode-se arriscar afirmar que os lugares públicos criados não passam de cenários para uma sociedade fictícia que, por sua vez, produzem uma estetização das relações sociais. Efetivamente, os Estados capitalistas modernos investem em obras monumentais justificadas pela ideologia da criação de locais públicos. Funcionam, contudo, como grandes vitrines publicitárias, como exemplificam os casos de Bilbau, Barcelona ou Paris. São as cidades-vitrines. A aspiração de pôr a cidade no novo mapa do mundo é perseguida por hábeis gestores do city marketing que pretendem fabricar também uma nova cidadania, um novo modo de ser e viver na cidade.

Esse modus vivendi articula-se a processos de socialização com pautas e estilos de vida estimulados pelos meios de comunicação. É o que se chama de "cidade espetáculo" (SÁNCHEZ, 2001).

Sánchez (2001), ao discutir a reinvenção das cidades na virada do século XX para o XXI, lembra que representar a totalidade, o todo social, implica poder: implica construção de hegemonia, capacidade de convencimento, criação de consenso. Os atores que participam do campo político de construção das imagens-cidade esforçam-se para tornar dominantes as imagens e as propagandas que produzem, utilizando "estratégias discursivas, meios e instrumentos para sua difusão e legitimação em variadas escalas". Porém, explica a autora, nesse campo político há relações de força também escalares (local-global) que incidem sobre as escolhas econômicas e simbólicas, capazes de produzir "imagens fortes" utilizadas como city marketing. Afirmando existir, a partir da década de 1990, um "mercado mundial de cidades", indica que este é movido e movimenta outros mercados, entre eles o turístico. A reinvenção de cidades a que estaríamos assistindo promove assim a sua espetacularização e molda as representações acerca de sua transformação.

No contrajogo dessa atitude de marketing é que, ironicamente, quanto mais as cidades buscam se diferenciar umas das outras, por meio de sua valorização patrimonial, mais se assemelham. Portanto, a construção da imagem da cidade está intrinsecamente ligada a representações e ideias. E efetivamente, a pasteurização das culturas e a "parque-tematização" parecem ser os caminhos mais proveitosos dos programas de renovação urbana contemporâneos, promovendo uma "ordem branca da cultura", teatros da memória que procuram avançar sobre os enclaves resistentes (ACSELRAD, 2009, pp. 185-186).

A semelhança que fala Acselrad é o que se vê quando se visita cidades colonizadas por imigrantes germânicos. Joinville entra nesta esteira, assim como Blumenau, Jaraguá do Sul e outras tantas. As casas em estilo enxaimel e de arquitetura teuto-brasileira são as que em primeiro lugar foram e são preservadas pelos órgãos de proteção patrimonial. 


\section{CONSIDERAÇÕES}

A espetacularização das cidades é tema que vem sendo discutido já desde o início dos anos 1990. E é uma questão que atinge todas as cidades que se preocupam de alguma forma com o seu patrimônio. Através de fundações culturais, comissões de patrimônio, órgãos gestores do turismo e da cultura, enfim, por meio da agenda pública que molda e ressignifica a cidade a partir de um ideal identitário.

O fato da descaracterização da fachada da Casa Boehm, em sua pintura não é um caso isolado. Nem mesmo o abuso quanto se fala das comunicações visuais e demais aspectos das cidades modernas (fios elétricos, postes, ruas estreitas etc). Assim vista da mesma forma, quando se trata das enchentes, bastante recorrente no centro da cidade. Todos esses fatos afetam diretamente o bem patrimonializado.

No entanto, esta afetação ao bem cultural é suplantado a ele mesmo, quando se vê que esses acontecimentos se repetem em outros diversos casos. Portanto, todos estes problemas são assunto corrente nas reuniões da COMPHAAN.

Percebi que, nas reuniões da COMPHAAN, há dois grupos bem definidos dentro da Comissão e que corriqueiramente discutem entre si, por suas posições "contrárias". Se não contrárias, no mínimo, dissonantes. Um grupo, formado majoritariamente por arquitetos, engenheiros e bombeiros, defende uma posição legalista, ou seja, apesar de idealizarem uma preservação do patrimônio de Joinville, levam em consideração, em primeiro lugar a lei, não importando o quão possivelmente falha, ineficiente e questionável seja. O outro grupo, formado por historiadores, jornalistas, advogados e arqueólogos, defensor da posição preservacionista, critica a lei vigente, não se importando com o seu poder vinculante perante às suas decisões, como Colegiado.

Observei que por diversas vezes certas discussões fizeram com que esses dois grupos se sobrepuseram à questão legal e levaram a Comissão a questionar a lei em sua eficácia ao invés de "simplesmente", como os defensores da lei dizem, decidir por uma liberação ou não.

Desta forma, o patrimônio das cidades e a sua autenticidade ficam nas mãos dessas pessoas, experts por terem conhecimento técnico e especializado, sendo consideradas aptas para fazer escolhas. Entretanto me questiono, para finalizar, até que ponto as escolhas acolhem todos os grupos sociais ali viventes? E mais, até quando Joinville será considerada por sua identidade germânica?

Estas perguntas não poderão ser respondidas aqui, por falta de "espaço", porém espero poder respondê-las em minha pesquisa de tese de Doutorado.

\section{REFERÊNCIAS:}

ACSELRAD, Henri (org). A duração das cidades: sustentabilidade e risco nas políticas urbanas. Rio de Janeiro: Lamparina, 2009. 256 p. 
ALTHOFF, Fátima Regina. Políticas de preservação do patrimônio edificado catarinense: a gestão do patrimônio urbano de Joinville. (Dissertação de Mestrado) Pós Graduação em urbanismo, história e arquitetura da cidade. UFSC. 2008. 210 p.

BENEVOLO, Leonardo. A cidade pós-liberal. In: História da cidade. São Paulo: Perspectiva, [1991], 2009.

CASTELLS, Alicia Norma Gonzales de; NARDI, Leticia. (org) Patrimônio cultural e cidade contemporânea. Florianópolis: Editora da UFSC, 2012. 280 p.

CERTEAU, Michel de. A invenção do cotidiano. 1. Artes de fazer. Petropolis: Vozes, Original Francês, [1990], 2013.

CHOAY, Françoise. O patrimônio em questão: Antologia para um combate. Trad. João Gabriel Alves Domingos. Belo Horizonte: Fino Traço, 2011. 184 p.

GIDDENS, Anthony. As consequências da modernidade. São Paulo: Unesp, 1991.

LOPES, Aderbal Rodrigo Castellan. Memória urbana: diagnóstico do patrimônio cultural no bairro Centro de Joinville. Dissertação de Mestrado em Patrimônio Cultural e Sociedade. Universidade da Região de Joinville. Joinville: UNIVILLE, 2011. 207 p.

MCCRACKEN, Grant. Cultura e consumo: uma explicação teórica da estrutura e do movimento do significado cultural dos bens de consumo. RAE, v. 47, n.1, jan/mar 2007. Trad. Fernando Eugênio. Revisão técnica: Everardo Rocha. Rio de Janeiro: Mauad, 2003. (Coleção Cultura e Consumo/coordenação Everardo Rocha).

MENESES, Ulpiano Bezerra de. Os 'usos culturais' da cultura: contribuição para uma abordagem crítica das práticas e políticas culturais. In: YÁZIGI, Eduardo; CARLOS, Ana Fani Alessandrini \& CRUZ, Rita de Cássia Ariza da (orgs.). Turismo: espaço, paisagem e cultura. 2. ed. São Paulo: Hucitec, 1999, pp. 88-99 (Col. "Geografia: teoria e realidade", vol. $30)$.

SANCHEZ, Fernanda. A reinvenção das cidades na virada de século: Agentes, estratégias e escalas de ação política. Rev. Sociol. Polit, Curitiba, n 16, pp.31-49, jun, 2001

SILVEIRA, Flavio Leonel Abreu da, BEZERRA, Marcia. Educação Patrimonial: Perspectivas e dilemas. In: LIMA FILHO, Manuel Ferreira, BELTRÃO Jane Felipe, ECKERT, Cornelia. (org) Antropologia e patrimônio cultural: diálogos e desafios contemporâneos. Blumenau: Nova Letra, 2007. 
YAZIGI, Eduardo. A conceituação de patrimônio ambiental urbano em países emergentes. Revista GeoINova, Nova Lisboa, Portugal, n 12, pp.65-82, 2006.

(C) Copyright Christiane Heloisa Kalb, Maria Bernardete Ramos Flores y Revista GeoGraphos, 2016. Este artículo se distribuye bajo una Licencia Creative Commons Reconocimiento-NoComercial 4.0 Internacional.

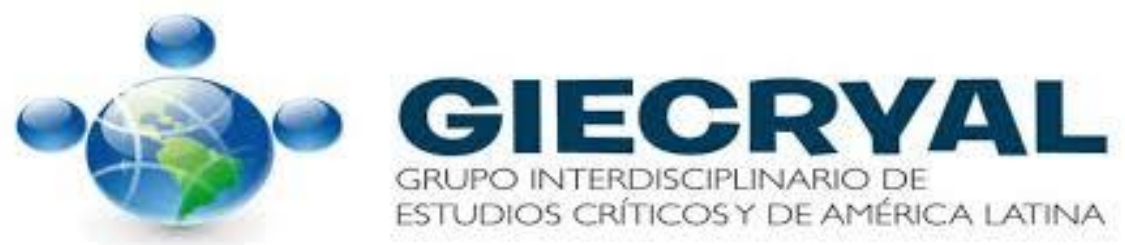

